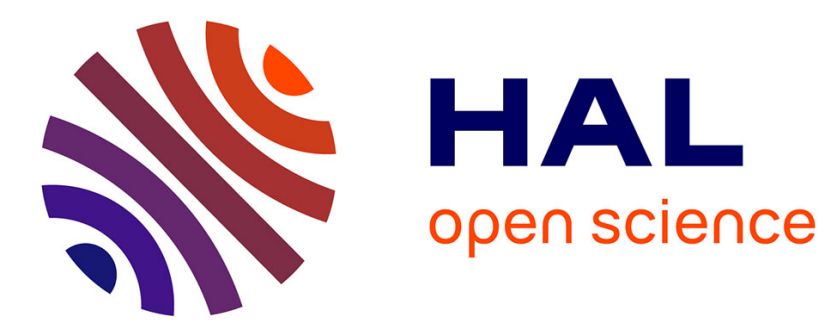

\title{
Active Suspension Control to Improve Passengers Comfort and Vehicle's Stability
}

Abbas Chokor, Reine Talj, Ali Charara, Hassan Shraim, Clovis Francis

\section{To cite this version:}

Abbas Chokor, Reine Talj, Ali Charara, Hassan Shraim, Clovis Francis. Active Suspension Control to Improve Passengers Comfort and Vehicle's Stability. 19th IEEE International Conference on Intelligent Transportation Systems (ITSC 2016), Nov 2016, Rio de Janeiro, Brazil. pp.296-301. hal-01378707

\section{HAL Id: hal-01378707 https://hal.science/hal-01378707}

Submitted on 10 Oct 2016

HAL is a multi-disciplinary open access archive for the deposit and dissemination of scientific research documents, whether they are published or not. The documents may come from teaching and research institutions in France or abroad, or from public or private research centers.
L'archive ouverte pluridisciplinaire HAL, est destinée au dépôt et à la diffusion de documents scientifiques de niveau recherche, publiés ou non, émanant des établissements d'enseignement et de recherche français ou étrangers, des laboratoires publics ou privés. 


\title{
Active Suspension Control to Improve Passengers Comfort and Vehicle's Stability
}

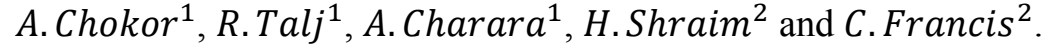

\begin{abstract}
This paper aims to control roll, pitch and vertical displacement of the suspended mass in a passenger vehicle during on-road drive by means of controlling the active suspension system. One of the goals of this control is to isolate the suspended mass in the vehicle from any road perturbation to ensure a big amount of comfort to the passengers (less roll, less pitch and less vibrations). Two strategies are used: the first one is based on the adaptive super-twisting second order sliding mode control, while the second one lies on the Lyapunov theory. We validate both strategies on a double lane change test, and a slalom steering test at $100 \mathrm{~km} / \mathrm{h}$. For this purpose, in addition to the active suspension control, we develop a full-vehicle model that presents reliable results in many situations during maneuver like road-bends, bumps, braking and accelerations.
\end{abstract}

\section{INTRODUCTION}

A vehicle may maneuver in normal situation (straight road, bends, bumps) or faces critical situations like avoiding other vehicles and hard cornering. In all these cases the driver may behave in a wrong way; sudden or hard steering will create a lateral acceleration on the vehicle's body which leads to an aggressive roll rotation of the suspended mass; sudden braking or hard accelerating will create a longitudinal acceleration which leads to a pitch rotation of the suspended mass. Besides these actions, and in addition to the road perturbations a vertical displacement may occur on the suspended mass. The latter is then exposed to roll, pitch and vertical displacement.

The suspension system acts on each corner of the vehicle to attenuate the negative effects of these behaviors and to guarantee a specific performance of the suspended mass. The choice of the kind and the parameters of the suspension system can modify this performance. There are three kinds of suspension system, the passive, semi-active and active suspension system which are described in [1].

In this paper, we will discuss the control of the active suspension system formed by a spring, a damper and an actuator to develop an added active force in order to balance the undesirable loads transfer to reject roll, pitch and vertical displacement of the suspended mass in a passenger vehicle, which leads to isolate the chassis from any perturbation and improves passengers comfort. To do that, we will develop in Section II a credible full vehicle model that matches with many situations during maneuver like road-bends, bumps, braking and accelerations. This model will be used to validate the performances of our controllers developed in Section III, the first controller is based on the adaptive super-twisting second order sliding mode control; and the second one is based on Lyapunov's equations. The goal of these controllers is to isolate the chassis from any road perturbation by ensuring less roll, pitch and vertical displacement of the suspended mass. In Section IV we will validate these controllers using Matlab/Simulink. Finally, conclusion and perspectives are presented in Section V.

\section{FULL VEHICLE MODEL}

\section{A. Vertical model}

\section{1) Quarter vehicle vertical model}

Fig.1 shows the quarter vehicle vertical model, where $m_{s}$, $m_{u s}, k_{t}, c_{t}, k_{s}, c_{s}, \mathrm{U}, F_{s}$, and $F_{z}$, are respectively, the quarter vehicle suspended mass, unsuspended mass, tire stiffness coefficient, tire damping coefficient, suspension stiffness coefficient, suspension damping coefficient, actuator force of the active suspension system (active force), total suspension force and vertical force on the wheel. $z_{s}$ and $z_{u s}$ are respectively the vertical displacement of the suspended mass and the unsuspended mass, $z_{r}$ and $g$ are respectively the vertical profile of the road and the gravitational constant.

Around the equilibrium, the equations that describe the system variations are:

$$
\begin{gathered}
F_{s}=-k_{s}\left(z_{s}-z_{u s}\right)-c_{s}\left(\dot{z}_{s}-\dot{z}_{u s}\right)+U \\
\ddot{z}_{u s}=-m_{u s} g-F_{s}+F_{z} \\
F_{z}=-k_{t}\left(z_{u s}-z_{r}\right)-c_{t}\left(\dot{z}_{u s}-\dot{z}_{r}\right)
\end{gathered}
$$

1. Sorbonne universités, Université de technologie de Compiègne, CNRS, Heudiasyc UMR 7253, CS 60 319, 60203 Compiègne, France; abbas.chokor@utc.fr; $\quad \underline{\text { reine.talj@hds.utc.fr; }}$ ali.charara@hds.utc.fr

2. Université Libanaise, Faculté de Génie, Centre de Recherche Scientifique en Ingénierie (CRSI), hassan.shraim@gmail.com; cfrancis@ul.edu.lb

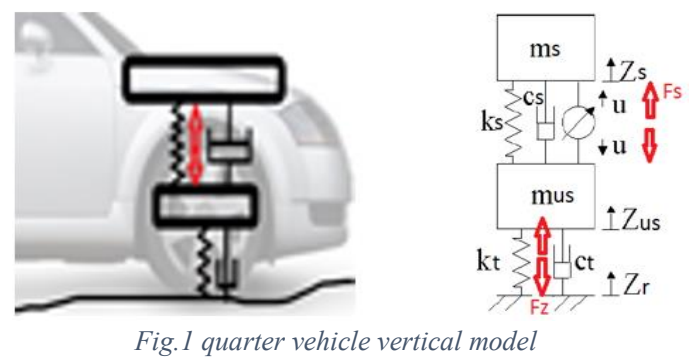


To express $z_{s}$ and $\dot{z}_{s}$, we need to develop the full vehicle vertical model

\section{2) Full vehicle vertical model}

In order to express each corner vertical displacement, and to express the roll, pitch and center of gravity vertical displacement, we will develop, in the following, a full vehicle vertical model (see Fig.2).

Equations (1), (2) and (3) are valid for each corner, let $i=$ $\{f, r\}$ index for front and rear, and $j=\{r, l\}$ index for right and left respectively.

$$
\begin{gathered}
F_{s_{i j}}=-k_{s_{i j}}\left(z_{s_{i j}}-z_{u s_{i j}}\right)-c_{s_{i j}}\left(\dot{z}_{s_{i j}}-\dot{z}_{u s_{i j}}\right)+U_{i j} \\
\ddot{z}_{u s_{i j}}=-m_{u s_{i j}} g-F_{s_{i j}}+F_{z_{i j}} \\
F_{z_{i j}}=-k_{t_{i j}}\left(z_{u s_{i j}}-z_{r_{i j}}\right)-c_{t_{i j}}\left(\dot{z}_{u s_{i j}}-\dot{z}_{r_{i j}}\right)
\end{gathered}
$$

Let $\theta, \varphi$ and $z$ be respectively the roll, pitch and vertical displacement of the suspended mass, then each corner vertical displacement $z_{s_{i j}}$ can be written as a function of these three states variables $(\theta, \varphi$ and $z)$.

$$
\begin{aligned}
& z_{s_{f r}}=z-t_{f} \sin \theta-l_{f} \sin \varphi \\
& z_{s_{f l}}=z+t_{f} \sin \theta-l_{f} \sin \varphi \\
& z_{s_{r r}}=z-t_{r} \sin \theta+l_{r} \sin \varphi \\
& z_{s_{r l}}=z+t_{r} \sin \theta+l_{r} \sin \varphi
\end{aligned}
$$

where $t_{f}, t_{r}, l_{f}$ and $l_{r}$ are respectively half front track, half rear track, wheelbase to the front and wheelbase to the rear.

$\dot{z}_{s_{i j}}$ are calculated by time derivative the four above equations.

$$
\begin{aligned}
& {\dot{z_{s}}}_{f r}=\dot{z}-t_{f} \dot{\theta} \cos \theta-l_{f} \dot{\varphi} \cos \varphi \\
& \dot{z_{s}}=\dot{z}+t_{f} \dot{\theta} \cos \theta-l_{f} \dot{\varphi} \cos \varphi \\
& \dot{z}_{s_{r r}}=\dot{z}-t_{r} \dot{\theta} \cos \theta+l_{r} \dot{\varphi} \cos \varphi \\
& \dot{z}_{s_{r l}}=\dot{z}+t_{r} \dot{\theta} \cos \theta+l_{r} \dot{\varphi} \cos \varphi
\end{aligned}
$$

The dynamics $\ddot{\theta}, \ddot{\varphi}$ and $\ddot{z}$ of the suspended mass are determined using the suspensions' forces $F_{s_{i j}}$, the effect of the lateral acceleration $a_{y}$ and the longitudinal acceleration $a_{x}$. $M_{s}, h_{\theta}$ and $h_{\varphi}$ are respectively the total suspended mass, the distance between the center of gravity of the suspended mass and the roll rotation center and the distance between the center of gravity of the suspended mass and the pitch rotation center. $I_{x}$ and $I_{y}$ are respectively the moment of inertia of the suspended mass around $\mathrm{x}$ axis and $\mathrm{y}$ axis.

$$
\begin{gathered}
\ddot{\theta}=\left\{\begin{array}{c}
\left(-F_{s_{f r}}+F_{s_{f l}}\right) t_{f}+\left(-F_{s_{r r}}+F_{s_{r l}}\right) t_{r} \\
+M_{s}\left(h_{\theta}+z\right) a_{y}
\end{array}\right\} / I_{x} \\
\ddot{\varphi}=\left\{\begin{array}{c}
-\left(F_{s_{f r}}+F_{s_{f l}}\right) l_{f}+\left(F_{s_{r r}}+F_{s_{r l}}\right) l_{r} \\
+M_{s}\left(h_{\varphi}+z\right) a_{x}
\end{array}\right\} / I_{y} \\
\ddot{z}=\left\{F_{s_{f r}}+F_{s_{f l}}+F_{s_{r r}}+F_{s_{r l}}-M_{s} g\right\} / M_{s}
\end{gathered}
$$

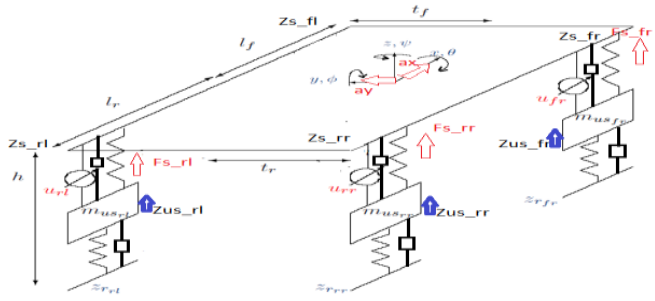

Fig.2 Full-vehicle vertical model

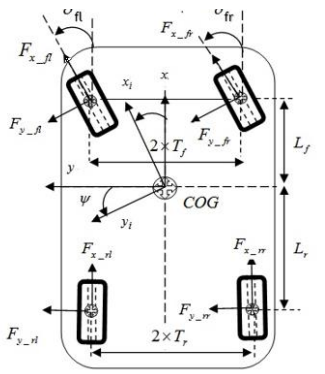

Fig. 3 Horizontal plan vehicle representation

To calculate $a_{x}$ and $a_{y}$, we need to develop the model of the lateral and longitudinal vehicle dynamics.

\section{B. Lateral and longitudinal vehicle models}

Let $\delta_{f l}$ and $\delta_{f r}$ the front wheels steer angles (left and right respectively), let $F_{x_{i j}}$ and $F_{y_{i j}}$ respectively the longitudinal and lateral forces applied to the wheel ij (see Fig. 3), $F_{x_{i j}}$ and $F_{y_{i j}}$ depend on $F_{z_{i j}}$ and are calculated from the Dugoff tire forces model presented in [3].

$$
\begin{gathered}
\ddot{x}=\dot{y} \dot{\Psi}+\left(F_{x_{f l}} \cos \delta_{f l}+F_{x_{f r}} \cos \delta_{f r}+F_{x_{r l}}+F_{x_{r r}}-\right. \\
\left.F_{y_{f l}} \sin \delta_{f l}-F_{y_{f r}} \sin \delta_{f r}\right) / M \\
a_{x}=\ddot{x}-\dot{y} \dot{\Psi} \\
\ddot{y}=-\dot{x} \dot{\Psi}+\left(F_{x_{f l}} \sin \delta_{f l}+F_{x f r} \sin \delta_{f r}+F_{y_{r l}}+F_{y_{r r}}\right. \\
\left.+F_{y_{f l}} \cos \delta_{f l}+F_{y_{f r}} \cos \delta_{f r}\right) / M \\
a_{y}=\ddot{y}+\dot{x} \dot{\Psi} \\
\ddot{\Psi}=\left\{-t_{f}\left(\cos \delta_{f l} F_{x_{f l}}-\cos \delta_{f r} F_{x_{f r}}+\sin \delta_{f r} F_{y_{f r}}-\right.\right. \\
\left.\sin \delta_{f l} F_{y_{f l}}\right)+l_{f}\left(\sin \delta_{f l} F_{x_{f l}}+\sin \delta_{f r} F_{x_{f r}}+\right. \\
\left.\cos \delta_{f l} F_{y_{f l}}+\cos \delta_{f r} F_{y_{f r}}\right)-l_{r}\left(F_{y_{r l}}+F_{y_{r r}}\right)- \\
\left.t_{r}\left(F_{x_{r l}}-F_{x_{r r}}\right)\right\} / I_{z}
\end{gathered}
$$

where $a_{x}, a_{y}$ and $\ddot{\Psi}$ are respectively the longitudinal acceleration, the lateral acceleration, and the yaw acceleration, $\mathrm{M}$ is the total vehicle mass and $I_{z}$ is the moment of inertia of the vehicle around $\mathrm{z}$ axis.

\section{CONTROLLeRS DESIGN}

In order to control roll, pitch and vertical displacement, we notice that the control inputs in (15), (16) and (17) are inside $F_{s_{i j}}$, they are the active forces (actuators outputs $U_{i j}$ ) described 
in (4). The system is over-actuated since $\theta, \varphi$ and $z$ are the state variables to be controlled and $U_{f r}, U_{f l}, U_{r r}$ and $U_{r l}$ are the control inputs.

We define intermediate control inputs as follows:

$$
\begin{gathered}
E_{\theta}=\left(-F_{s_{f r}}+F_{s_{f l}}\right) t_{f}+\left(-F_{s_{r r}}+F_{s_{r l}}\right) t_{r} \\
E_{\varphi}=-\left(F_{s_{f r}}+F_{s_{f l}}\right) l_{f}+\left(F_{s_{r r}}+F_{s_{r l}}\right) l_{r} \\
E_{z}=F_{s_{f r}}+F_{s_{f l}}+F_{s_{r r}}+F_{s_{r l}}
\end{gathered}
$$

These equations can be written in the form

$$
\left(\begin{array}{c}
E_{\theta} \\
E_{\varphi} \\
E_{z}
\end{array}\right)=\underbrace{\left(\begin{array}{cccc}
-t_{f} & t_{f} & -t_{r} & t_{r} \\
-l_{f} & -l_{f} & l_{r} & l_{r} \\
1 & 1 & 1 & 1
\end{array}\right)}_{A}\left(\begin{array}{l}
F_{s_{f r}} \\
F_{s_{f l}} \\
F_{s_{r r}} \\
F_{s_{r l}}
\end{array}\right)
$$

Then, the system to be controlled, given by the equations (15), (16) and (17), can be rewritten as:

$$
\left\{\begin{array}{l}
\ddot{\theta}=\left\{E_{\theta}+M_{s}\left(h_{\theta}+z\right) a_{y}\right\} / I x \\
\ddot{\varphi}=\left\{E_{\varphi}+M_{s}\left(h_{\varphi}+z\right) a_{x}\right\} / I y \\
\ddot{z}=\left\{E_{z}-M_{s} g\right\} / M_{s}
\end{array}\right.
$$

Where $E_{\theta}, E_{\varphi}$ and $E_{z}$ are the new control inputs to the system.

In section (III.A.1) and (III.A.2) we will develop two higher level controllers, respectively, the adaptive super twisting second order sliding mode control and a controller based directly on the Lyapunov's theory, where $E_{\theta}, E_{\varphi}$ and $E_{z}$ are the higher level control inputs to control the state variables $\theta, \varphi$ and $z_{s}$ and let them follow respectively the desired reference variables $\theta_{\text {des }}, \varphi_{\text {des }}$ and $z_{\text {des }}$.

In section (III.B) we will develop the low level controller where $U^{*}{ }_{i j}$ are the control inputs to the system.

$$
\begin{aligned}
& \text { Let } \quad e_{\theta}=\theta-\theta_{\text {des }} \\
& e_{\varphi}=\varphi-\varphi_{\text {des }} \\
& e_{z}=z-\mathrm{z}_{\text {des }}
\end{aligned}
$$

the errors between the three states and their corresponding desired variables.

\section{A. Higher level controllers}

1) Adaptive super twisting second order sliding mode control

This controller aims at reducing the roll, pitch and vertical displacement errors and their time derivatives, their corresponding sliding variables are chosen as follows:

$$
\begin{gathered}
s_{\theta}=\dot{e}_{\theta}+k_{\theta} e_{\theta} \\
s_{\varphi}=\dot{e}_{\varphi}+k_{\varphi} e_{\varphi} \\
s_{z}=\dot{e}_{z}+k_{z} e_{z}
\end{gathered}
$$

where $k_{\theta}, k_{\varphi}$ and $k_{z}$ are positive control parameters to be adjusted.
The control inputs $E_{\theta}, E_{\varphi}$ and $E_{z}$ are in the form:

$$
\begin{gathered}
E_{\theta}=E_{1 \theta}+E_{2 \theta}+E_{e q \theta} \\
E_{\varphi}=E_{1 \varphi}+E_{2 \varphi}+E_{e q \varphi} \\
E_{z}=E_{1 z}+E_{2 z}+E_{e q z} \\
\left\{\begin{array}{c}
E_{1 \mathrm{i}}=-\alpha_{i}\left|s_{i}\right|^{1 / 2} \operatorname{sign}\left(s_{i}\right) \\
\dot{E}_{2 \mathrm{i}}=-\beta_{i} \operatorname{sign}\left(s_{i}\right) \\
i=\theta ; \varphi ; z .
\end{array}\right.
\end{gathered}
$$

( $\alpha_{i}$ and $\beta_{i}$ are also controller gains to be adjusted).

and $E_{e q \theta}, E_{e q \varphi}$ and $E_{e q z}$ are respectively $E_{\theta}, E_{\varphi}$ and $E_{z}$ when $\dot{S}_{i}=0$. After some simple calculations, we can find:

$$
\begin{gathered}
E_{e q \theta}=-M_{s}\left(h_{\theta}+z\right) a_{y}+I_{x} \ddot{\theta}_{d e s}-k_{\theta} I_{x}\left(\dot{\theta}-\dot{\theta}_{d e s}\right) \\
E_{e q \varphi}=-M_{s}\left(h_{\varphi}+z\right) a_{x}+I_{y} \ddot{\varphi}_{d e s}-k_{\varphi} I_{y}\left(\dot{\varphi}-\dot{\varphi}_{d e s}\right) \\
E_{e q z}=M_{s} g+M_{s} \ddot{z}_{d e s}-k_{z} M_{s}\left(\dot{z}-\dot{z}_{\text {des }}\right)
\end{gathered}
$$

The super-twisting sliding mode controller is known for its robustness against parameters uncertainties and disturbances. It converges to the sliding surface in finite time. However, it could cause chattering once the equilibrium is reached. For that reason, the controller is made adaptive by multiplying the gains $\alpha_{i}$ and $\beta_{i}$ by $\frac{\left|s_{i}\right|}{\left|s_{i}\right|+\varepsilon_{i}}$, where $\varepsilon_{i}$ are small positive constants. The aim of such term is to attenuate the controller gains near to the equilibrium, and then reduce chattering; while maintaining the gains far away from the equilibrium to guarantee fast convergence.

\section{2) Controller based on the Lyapunov theory}

This controller aims at reducing the roll, pitch and vertical displacement errors, and their time derivatives by ensuring exponential convergences. Let $V_{i}=\frac{1}{2} s_{i}{ }^{2}$ positive definite Lyapunov functions, their time derivative $\dot{V}_{l}=s_{i} \dot{s}_{l}$ should be negative, then $\dot{s}_{i}=-\alpha_{i} s_{i}$, where $\alpha_{i}$ are positive gains to be adjusted, we add to the equations of roll and pitch their error time integrator to reduce steady state error.

$$
\begin{gathered}
s_{\theta}=\dot{e}_{\theta}+k_{1 \theta} e_{\theta}+k_{2 \theta} \int e_{\theta} d t \\
s_{\varphi}=\dot{e}_{\varphi}+k_{1 \varphi} e_{\varphi}+k_{2 \varphi} \int e_{\varphi} d t \\
s_{\mathrm{z}}=\dot{e}_{z}+k_{1 z} e_{z}
\end{gathered}
$$

$\dot{s}_{\theta}=\ddot{e}_{\theta}+k_{1 \theta} \dot{e}_{\theta}+k_{2 \theta} e_{\theta}=-\alpha_{\theta}\left(\dot{e}_{\theta}+k_{1 \theta} e_{\theta}+\right.$

$\left.k_{2 \theta} \int e_{\theta} d t\right), \quad \dot{s}_{\varphi}=\ddot{e}_{\varphi}+k_{1 \varphi} \dot{e}_{\varphi}+k_{2 \varphi} e_{\varphi}=-\alpha_{\varphi}\left(\dot{e}_{\varphi}+\right.$ $\left.k_{1 \varphi} e_{\varphi}+k_{2 \varphi} \int e_{\varphi} d t\right)$,

$\dot{s}_{\mathrm{z}}=\ddot{e}_{z}+k_{1 z} \dot{e}_{z}=-\alpha_{z}\left(\dot{e}_{z}+k_{1 z} e_{z}\right)$,

After some simple calculations, we can find the high level control inputs as follows:

$$
\begin{gathered}
E_{\theta}=-\left(\alpha_{\theta}+k_{1 \theta}\right) I_{x}\left(\dot{\theta}-\dot{\theta}_{d e s}\right)-\left(\alpha_{\theta} k_{1 \theta}+k_{2 \theta}\right) I_{x}\left(\theta-\theta_{d e s}\right) \\
-\alpha_{\theta} k_{2 \theta} I_{x} \int\left(\theta-\theta_{d e s}\right) d t-M_{s}\left(h_{\theta}+z\right) a_{y}+I_{x} \ddot{\theta}_{d e s} \\
E_{\varphi}=-\left(\alpha_{\varphi}+k_{1 \varphi}\right) I_{y}-\left(\alpha_{\varphi} k_{1 \varphi}+k_{2 \varphi}\right) I_{y}\left(\varphi-\varphi_{d e s}\right) \\
-\alpha_{\varphi} k_{2 \varphi} I_{y} \int\left(\varphi-\varphi_{d e s}\right) d t-M_{s}\left(h_{\varphi}+z\right) a_{x}+I_{y} \ddot{\varphi}_{d e s}
\end{gathered}
$$




$$
\begin{gathered}
E_{z}=-M_{s}\left(\alpha_{z}+k_{1 z}\right)\left(\dot{z}-\dot{z}_{\text {des }}\right)-\alpha_{z} k_{1 z} M_{s}\left(z-z_{\text {des }}\right)+ \\
M_{s} g+M_{s} \ddot{z}_{\text {des }}
\end{gathered}
$$

\section{B. Low level controller}

Once $E_{\theta}, E_{\varphi}$ and $E_{z}$ are obtained from one of the controllers discussed before, we can deduce $F s_{i j}$ by doing the pseudo-inverse matrix to (26), then we obtain:

$$
\left(\begin{array}{l}
F_{S_{f r}} \\
F_{S_{f l}} \\
F_{S_{r r}} \\
F_{S_{r l}}
\end{array}\right)=\left(A^{T} \cdot A\right)^{-1} \cdot A^{T}\left(\begin{array}{c}
E_{\theta} \\
E_{\varphi} \\
E_{z}
\end{array}\right)
$$

Finally, by substituting $F s_{i j}$ by their values in (4), we find the control outputs:

$U^{*}{ }_{i j}=F_{s_{i j}}+k_{s_{i j}}\left(z_{s_{i j}}-z_{u s_{i j}}\right)+c_{s_{i j}}\left(\dot{z}_{s_{i j}}-\dot{z}_{u s_{i j}}\right)$

We denoted by $U^{*}{ }_{i j}$ instead of $U_{i j}$ the controllers outputs because the actuators have some limitations.

\section{Actuators limitations}

The model of the actuator is not developed in this paper. However, in order to make the forces developed by the controller reliable, we need to take into consideration the actuator's limitations [9]:

- Time response $(0.1 \mathrm{sec})$.

- Maximum/minimum force values $(+/-9800 \mathrm{~N})$

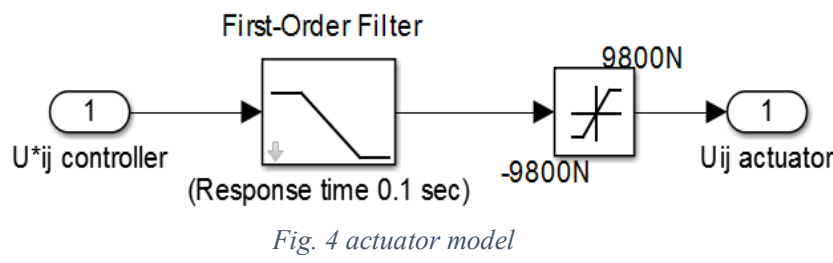

\section{SimUlation AND VALIDATION}

In this section, we will validate the two controllers developed in the previous section using two scenarios. All vehicle's and controllers numerical values parameters are defined in [11], here in Table 1 we cite the values (SI units) of some important parameters.

Table 1 Vehicle parameters

\begin{tabular}{|c|c|c|c|}
\hline $\mathrm{M}$ & 1286.4 & $t_{f}=t_{r}$ & 0.773 \\
\hline$m_{u s_{i j}}$ & 40 & $l_{f} \& l_{r}$ & $1 \& 1.6$ \\
\hline$I_{x}$ & 534 & $k_{s_{f l}}=k_{s_{f r}}$ & 22639 \\
\hline$I_{y}$ & 1860 & $k_{s_{r l}}=k_{s_{r r}}$ & 12548 \\
\hline$I_{z}$ & 1970 & $c_{s_{i j}}$ & 700 \\
\hline
\end{tabular}

The first scenario is a double lane change maneuver test after 10 seconds from starting the test (in the first 10 seconds a motor torque is applied to accelerate the vehicle to a desired speed), which is considered as a frequent situation that hardly solicits the lateral dynamics of the vehicle. The second scenario is a slalom test at $100 \mathrm{~km} / \mathrm{h}$ as starting speed, which is an aggressive situation that could drive the vehicle outside the stability region.
The goal is to isolate the suspended mass from any perturbation, then the desired variables are $\theta_{\text {des }}=0 ; \varphi_{\text {des }}=$ $0 ; z_{\text {des }}=0$.

\section{A. Double lane change maneuver}

The double lane change test is a widespread test, the front wheels steering angle is shown in Fig. 5.

Fig. 6 shows the motor torque applied to the rear wheels which can make a considerable acceleration to the body of the vehicle with a big amount of jerk.

The speed of the vehicle is shown in Fig. 7, it increases quickly in the first 10 seconds due to high motor torque and then slowly due to low torque.

As an influence on the body of the vehicle, we can notice the following. In the first 10 seconds, the suspended mass is exposed to a considerable pitch rotation in the open loop operation mode due to the motor torque applied to accelerate the vehicle (see Fig. 10). We can see clearly that the controllers improve the performance of the suspended mass by eliminating jerk effect, they suppress almost entirely the pitch rotation.

In the next 10 seconds, the suspended mass is exposed to a considerable roll rotation in the open loop operation mode due to the double lane change maneuver (see Fig. 9). We can see clearly also the improvement provided by the controllers that drastically decrease the lateral acceleration effect induced by the steering operation and suppress almost entirely the roll rotation.

Fig. 11 shows also the vertical displacement in controlled and open loop operation. This vertical displacement is a combination of all perturbations during maneuver and is considered as vibrations to be attenuated in order to ensure passengers comfort. Since the test solicits especially the roll motion, the vertical displacement is not highly disturbed, however, we can see clearly that with the proposed controllers, these vibrations are highly attenuated with respect to the open loop operation.

Fig. 8 shows the additive active forces of the suspension system on each corner, developed by the actuators to isolate the suspended mass from any perturbation. The developed forces are far from the saturation limit imposed by the actuators. To explain the controllers output chattering in the first 10 seconds, we notice that the vehicle suspended mass has very weak solicitations in this duration (roll, pitch and vertical displacement dynamics are near to zero), then the active forces demanded by the actuators should be small, but in fact, these forces are calculated by doing the pseudoinverse matrix described in (47) to a vector who has small values near to zero, which will cause problems in the internal dynamics and create these chattering.

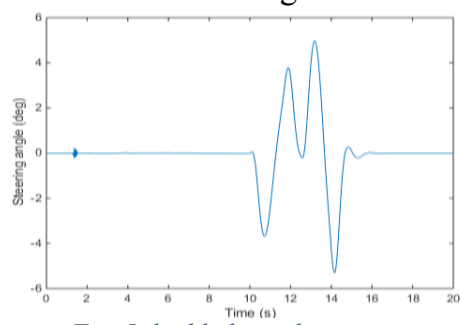

Fig. 5 double lane change steer 


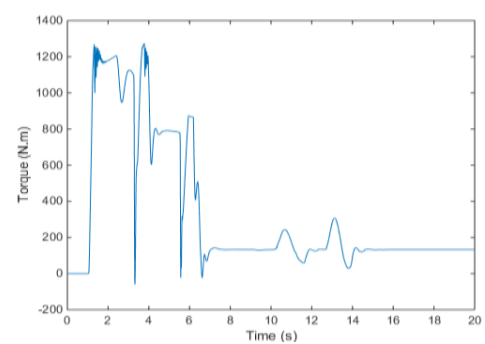

Fig. 6 Chicane motor torque

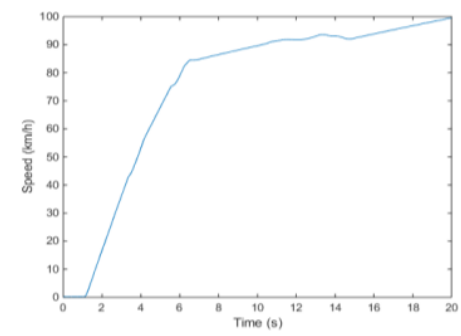

Fig. 7 Vehicle speed
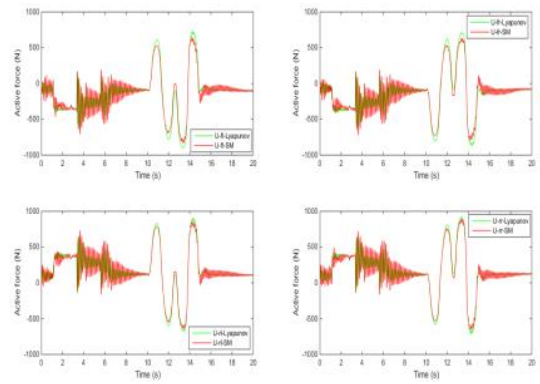

Fig. 8 actuators outputs (active forces)

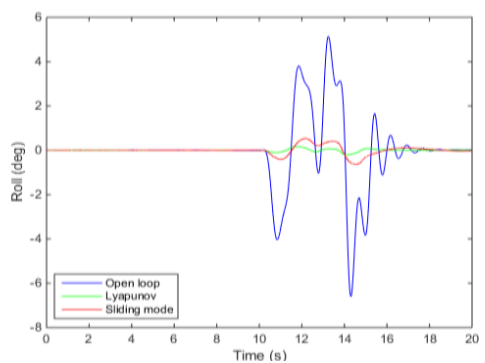

Fig. 9 Roll rotation of the suspended mass

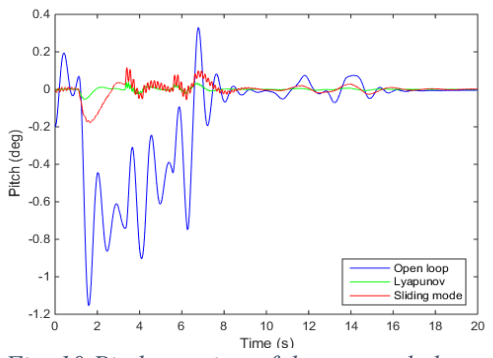

Fig. 10 Pitch rotation of the suspended mass

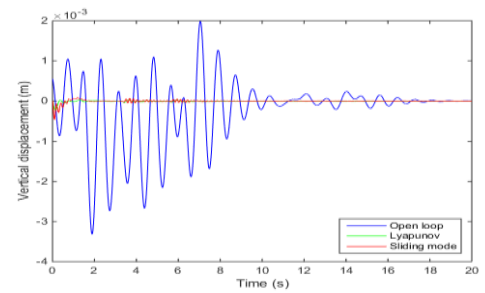

Fig. 11 Vertical displacement of the suspended mass

\section{B. Slalom steering test at $100 \mathrm{~km} / \mathrm{h}$}

The slalom steering test is considered as an aggressive test to make sure that the suspension system is still efficient. In our paper we use it to validate that the active suspension system can isolate the suspended mass even under hard situations and at high speed. From this test we can also deduce that if the driver steers suddenly at a high speed avoiding an obstacle, the vehicle could remain stable and under control.

Fig. 12 shows the front wheels steering angle with an increasing amplitude at a frequency of $0.5 \mathrm{~Hz}$ which is considered as an aggressive steering.

The speed of the vehicle decreases with time due to the aggressive slalom steering without motor torque besides road friction, and is shown in Fig. 13.

Fig. 14 shows the additive active forces of the suspension system on each corner, developed by the actuators to isolate the suspended mass from any perturbation. We can notice that both controllers provide almost similar control inputs.

Fig. 15 shows the roll response in the open-loop and closed-loop with both controllers. It is obvious that without controllers the suspended mass has a high roll rotation that reaches 6 degrees. However in the controlled operation mode the roll rotation of the vehicle is highly reduced.

Fig. 16 shows the pitch response of the suspended mass with and without controllers. Note that the pitch angle in the open loop operation case is not highly solicited in this maneuver. However, controlling the pitch angle may be critical in some other scenarios and the two controllers developed show a significant reduction of the pitch rotation with respect to the open loop case.

Fig. 17 shows the vertical displacement response of the suspended mass with and without controllers which is not very affected even in the open loop operation mode.

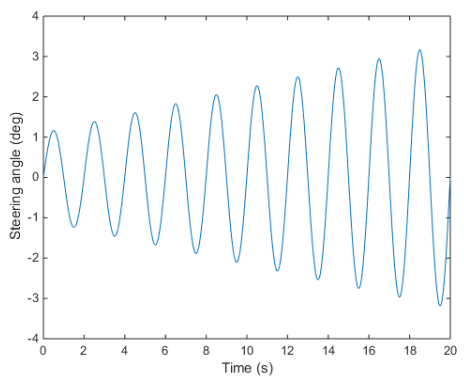

Fig. 12 Slalom steer front wheels angle

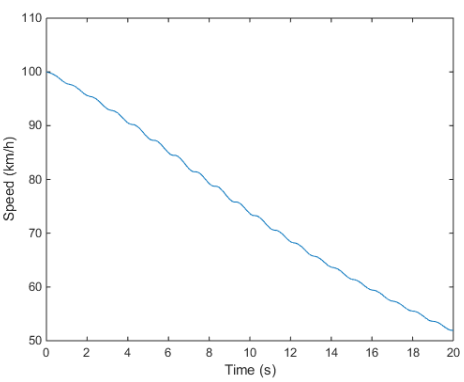

Fig. 13 Vehicle speed 

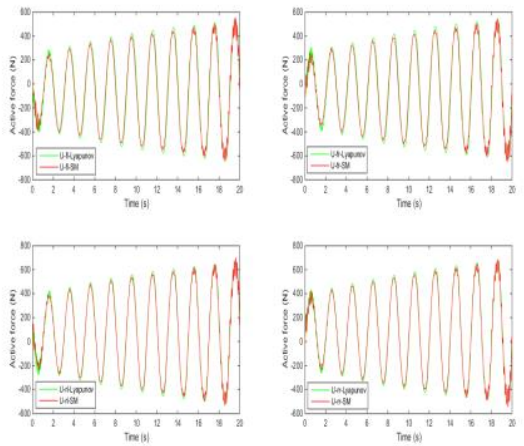

Fig. 14 Control inputs (active suspensions forces)

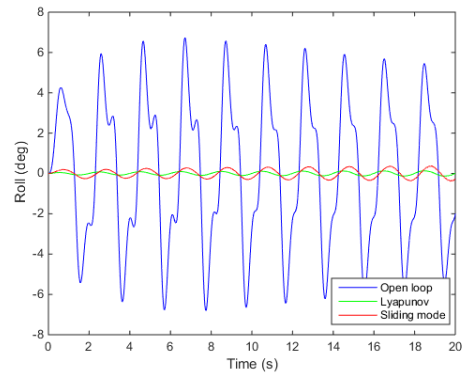

Fig. 15 Roll rotation of the suspended mass

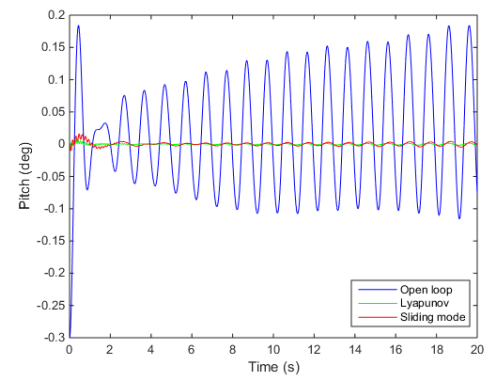

Fig. 16 Pitch rotation of the suspended mass

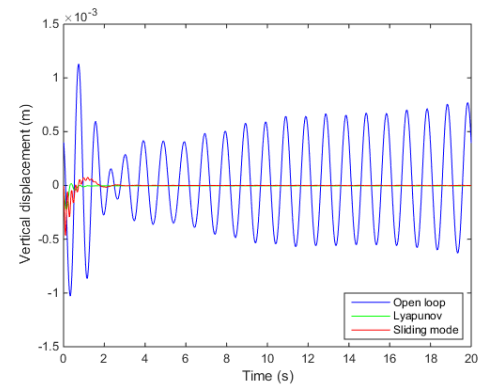

Fig. 17 Vertical displacement of the suspended mass

\section{CONCLUSION AND PERSPECTIVE}

The goal of this paper is to isolate the suspended mass from any perturbation by controlling the roll, pitch and vertical displacement of the chassis. Two different controllers have been proposed in this paper, the first is based on the supertwisting sliding mode approach, and the second is based on Lyapunov's theory. The objective is highly reached with both proposed control strategies, which have been validated on two test scenarios that solicit the vehicle in hard situations. We noticed that the active suspension control has high accuracy, it can suppress almost entirely roll, pitch and vertical displacement of the suspended mass in a passenger vehicle. Concerning a comparison between these two approaches, we can deduce that the controller based on Lyapunov theory has more accuracy, due to the chattering coming from manual adjusted gains in the Sliding mode controller. In our next work, we will validate these operated approaches using Scaner Studio simulator, we will also focus on how to improve the lateral dynamics (avoid oversteering and understeering) during maneuver on hard cornering by making a specific roll angle to compensate the loads transfers. We will emphasize the coordination between the active suspension control system and other stabilizing controllers as Active front steering, differential braking, etc., in order to improve their behaviors in a "Global Chassis Control" context.

\section{ACKNOWLEDGMENT}

This work was carried out and funded in the framework of the Labex MS2T. It has been also carried out in the framework of the French regional project SYSCOVI. SYSCOVI is jointly financed by the European Union. Europe engage in Picardie with the European Fund of Regional Development FEDER. It was supported by the French Government, through the program "Investments for the future" managed by the National Agency for Research (Reference ANR-11-IDEX-0004-02), also by Idex Sorbonnes Universités: Kit Master Nord-Sud, by the French Lebanese Research program CEDRE (32918PA).

\section{REFERENCES}

[1] C. Poussot-Vassal, Robust linear parameter varying multivariable automotive global chassis control, Ph.D. thesis, Grenoble INP, GIPSAlab., Control system dept., Grenoble, France, 2008.

[2] D. Sammier, Sur la modélisation et la commande de suspension de véhicules automobiles. Ph.D. thesis, INPG, France, 2001.

[3] R. Rajamani, Vehicle dynamics and control, New York: Springer, 2006.

[4] G. Baffet, Développement et validation expérimentale d'observateurs des forces du contact pneumatique/chaussée d'une automobile, Ph.D. thesis, UTC, France, 2007.

[5] B. Badji, Caractérisation du comportement non linéaire en dynamique du véhicule, Ph.D. thesis, UTBM, France, 2009.

[6] Z. Abd-Kadir et. Al, Active Roll Control Suspension System for Improving Dynamics Performance of Passenger Vehicle, in proc. of 2011 International Conference on Modelling, Identification and Control, Shanghai, China, June 26-29, 2011.

[7] C. Poussot-Vassal, O. Sename, and L. Dugard, A global chassis controller for handling improvements involving braking and steering systems, in Proc. of 47th IEEE Conf. on Decision and Control,Cancun, Mexico, 2008, pp. 5366-5371.

[8] C. Bardawil et. al, Integrated Control for Vehicle Lateral Dynamics Improvements using Second Order Sliding Mode 2014 IEEE Conference on Control Applications (CCA).

[9] A. Chamseddine, Méthodologie de diagnostic et tolérances aux défauts de systèmes complexes, Ph.D. thesis, Université Paul Cézanne, France 2007.

[10] A. Daher, master internship report, Centre de Recherche Scientifique en Ingénierie (CRSI), Faculté de Génie, Université Libanaise, Liban, 2015.

[11] A. CHOKOR, master internship report, HEUDIASYC, UMR CNRS 7253, Université de Technologie de Compiègne, Centre de Recherches de Royallieu, COMPIEGNE cedex, France. 